\title{
Origin of Diabetes Insipidus and Hypernatremia
}

\author{
Shigeyoshi Teramoto, Kaoru Iwayama, ${ }^{*}$ Masatoshi Yonfkura* \\ and Kazuo MORI* \\ Department of Neurosurgery, National Nagasaki Central Hospital \\ lool Kubara, Ohmura, Nagasaki, Japan \\ * Department of Neurosurgery, Nagasaki University' School of Medicine \\ 7-1 Sakamoto, Nagasaki, Japan
}

\begin{abstract}
Summary
There are few studies dealing with the pathophysiology in the central mechanism of water and electrolytes control. The osmoreceptors have been concerned in the region of the supraoptic and paraventricular nuclei (SON, PVN) which are also the area where $\mathrm{ADH}$ is formed. Investigations were made on the role of osmoreceptors in $\mathrm{ADH}$-releasing disorder and in experimentally induced diabetes insipidus in the cat and on the involvement of the lateral hypothalamus in these disorders as well as in hypernatremia resulting from disorders of osmoreceptors and the drinking or thirst centers. Daily intake and output, pre- and postoperative electrolytes and osmolarity in the serum and urine, plasma $\mathrm{ADH}$ and aldosterone were measured in three groups (normal, diabetes insipidus and hypernatremia cats).

Experimental diabetes insipidus was induced by the SON lesion on one side, while mild diabetes insipidus with concurrent development of hypernatremia was produced by the SON lesion and an injury to the lateral hypothalamus.
\end{abstract}

Key words:

diabctes insipidus, hypernatremia, osmoreceptor. lateral hypothalamus, antidiuretic hormone $(\mathrm{ADH})$, aldosterone

\section{Introduction}

In contrast to the extensive clinical literature concerning postoperative disturbances of water and the serum electrolytes in patients with hypothalamo-pituitary tumor, $8.21 .22 .27,29,33.38$. ${ }^{391}$ there are only a few studies dealing with the pathophysiology in the central mechanism of water and electrolytes control. ${ }^{30.36 .38)}$ Recently, it has been reported that there are many areas controlling the output of antidiuretic hormone $(\Lambda D H))^{4.5 .15,341}$ Osmoreceptors have been conccrned in the region of the supraoptic and paraventricular nuclei (SON, PVN) which are also the areas where ADH is formed since Verney's concept of the "Osmoreceptor." ${ }^{341}$ Changes in neural activities of the supraoptic nucleus induced by hypertonic infusion, stimulation of peripheral or central nervous structures, and pharmacological agents have been reported. ${ }^{4}$. $5.15 .16 .18 .35)$ Teramoto $^{32)}$ reported the effects of unilateral lesions of the SON on residual SON fuction for the pathophysiology of traumatic diabetes insipidus. Welt ${ }^{371}$ postulated a syndrome of essential hypernatremia, characterized by a new setting of cerebral osmoreceptors at a higher serum sodium or osmolarity level. Dorn and Rothballer ${ }^{7}$ produced experimentally essential hypernatremia by injuring presumed osmosensitive elements.

The present study was designed experimentally to test the origin of diabetes insipidus and hypernatremia unassociated with body fluid contraction or clinical signs of dehydration. Since what comes into question in the field of neurosurgery is the disorder of osmoreceptors, disorders of $\mathrm{ADH}$ secretion were investigated from a viewpoint of osmolarity. Investigations were made on the role of osmoreceptors in ADH-releasing disorders and in experimentally induced diabetes insipidus in the cat, and on the involvement of the lateral hypothalamus (regarded as the feeding and drinking cen- 
ters $)^{1.12,24)}$ in these disorders as well as in hypernatremia resulting from disorders of osmoreceptors and the drinking or thirst centers. ${ }^{2.11}$

\section{Materials and Methods}

Fifty-four healthy adult male cats weighing between 2.5 and $3.5 \mathrm{~kg}$ were used. Experiments were divided in three groups: 1) Normal cats, 2) Diabetes insipidus cats (unilateral lesion of the supraoptic nucleus) and 3$) \mathrm{Hy}$ pernatremia cats (unilateral lesion of the supraoptic nucleus and contralateral lesion of the lateral hypothalamus). In all three groups daily intake and output, pre- and postoperative electrolytes and osmolarity in serum and urine, and plasma ADH and aldosterone were measured.

The transoral approach for recording was performed in Flaxedil immobilized or urethane anesthetized cats (Fig. 1).The $3 \mathrm{M} \mathrm{KCl-filled} \mathrm{mi-}$ cropipettes or tungusten electrodes were introduced through the optic tracts after suitable exposure. The region of the supraoptic nucleus was reached after the disappearance of optic tract potential induced by photic stimulation. Osmosensitivities of the cells were ascertained by instillation of $2.0 \mathrm{ml}$ of $1 \mathrm{~mol}$ or $9.0^{\circ}$ o saline into the ipsilateral carotid artery catheterized through the lingual artery and antidromic stimulation of the pituitary stalk. Unit discharges were monitored and photographed on an oscilloscope, and a permanent record was kept on a tape recorder to count unit activity.

Depth electrodes consisting of well-insulated. except at the tip, nichrome wire for stimulation were inserted stereotactically into the lateral hypothalamus or the desired nuclei. The stimulatory potentials varied from 2-10 volts for the duration of 0.1 to $0.5 \mathrm{msec}$. Electrodes for coagulation purposes consisted of well-insulated

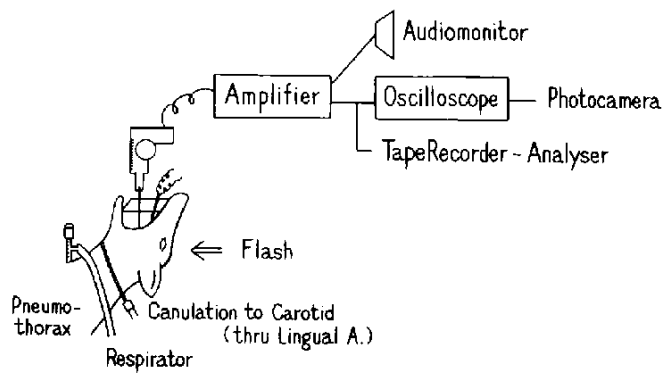

Fig. 1 Block diagram of experimental arrangement. nichrome wire with about $1 \mathrm{~mm}$ of their tips exposed. Currents used varied between 20 and 50 mamp for the duration of $30-120 \mathrm{sec}$. depending upon the site of the lesion desired. The extent of destruction and the position of recording or stimulatory depth electrodes were carefully checked in all animals by histological study of serial sections. Local anesthesia was used around the wound margins after the initial operative procedure employing short acting sodium pentobarbiturate.

\section{Results}

\section{Unit activities of the supraoptic nucleus in normal cats}

Extracellular recording of neurone activities of the supraoptic nucleus (SON), which is believed to function as osmoreceptors, in normal cats showed that many of the cells in the nucleus discharge at a frequency of 4-6 times per second, the discharge rate being nearly constant. Injection of $1.5 \mathrm{ml}$ of $9^{\circ}{ }_{\circ} \mathrm{NaCl}$ into the carotid artery caused the spontaneous discharge rate of the cells of the SON to increase for 1 to 2 minutes (Fig. 2). The lower portion of Figure 2 represents the firing frequency of these unit

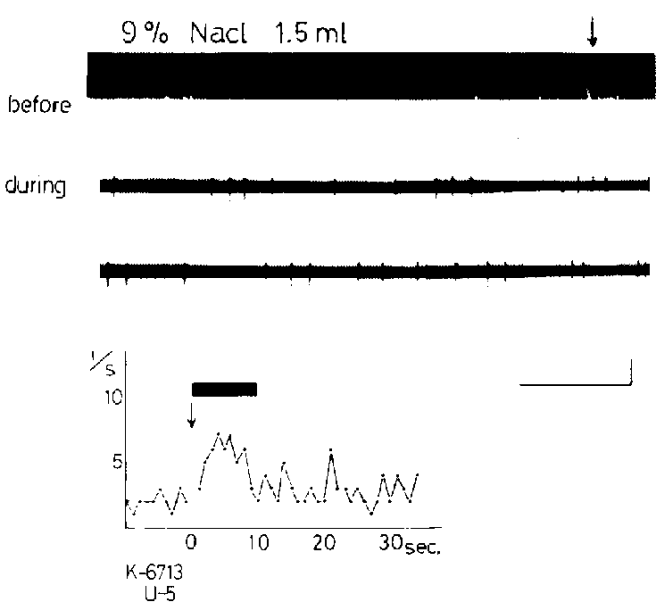

Fig. 2 The SON unit activities before and during hypertonic saline infusion. A vertical arrow indicates the beginning of infusion. Horizontal time scale and amplitude for $0.5 \mathrm{sec}$. and $1 \mathrm{mV}$ respectively. Lower curve plots a firing frequency of unit discharges, indicating clearly increased unit activities. A black rectangle represents infusion period. 
Table 1 Responses of the supuraoptic nucleus (SON) to hypertonic saline. (100 units from the Supuraoptic Nucleus)

\begin{tabular}{lcc}
\hline Hypertonic Saline, lmol. & Normal & Lesion \\
\hline Responsive & $41\left(68.3^{\circ} \%\right) 26(65.0 \%)$ \\
\hline decreased & $5\left(8.3^{\circ}{ }_{0}\right)$ & $4(10.0 \%$ \\
\hline Ton-responsive & $14(23.3 \%)$ & $10(25.0 \%)$ \\
\hline
\end{tabular}

discharges, indicating clearly increased unit activities during and after injection of hypertonic saline into the carotid artery,

These findings confirm the presence, location and general type of responses reported for hypothalamic units by Cross and Green, ${ }^{5}$ Brooks and associates, ${ }^{4)}$ Joynt $^{151}$ and others. ${ }^{9.10 .141}$

However, as is obvious from Table 1, an analysis of 60 units recorded from the SON of the anterior hypothalamus of normal cats showed that following injection of $1 \mathrm{~mol} \mathrm{NaCl}$ into the carotid artery the unit discharge rate increased in $68.3 \%$ of the instances, decreased in $8.3 \%$, and remained unaltered in $23.3 \%$. These figures are consistent with those reported previously by various authors.

In subsequent studies the effect of stimulation of other cerebral structures (e.g. frontal lobe, limbic system, reticular formation, cerebellum and vagus) on the unit discharge of the $\mathrm{SON}$ was investigated. Of these observations, those on the effect of stimulation of the ipsilateral hypothalamus, wherein the drinking center is thought to reside, on the electrical activity of the SON are presented in this communication (Fig. 3). In this particular experiment, the lateral hypothalamus was stimulated electrically at $100 \mathrm{~Hz}$ and 0.3 volts using chronically implanted electrodes. The unit discharge of the SON was inhibited while the lateral hypothalamus was being stimulated. Subsequently, it showed an increase for usually 30 seconds after termination of stimulation. With stimulation at $50 \mathrm{~Hz}$, on the other hand, inhibition of the electrical activity during stimulation was evident but the after-effect was not so marked as with stimulation at $100 \mathrm{~Hz}$. These responses to stimulation of the lateral hypothalamus were particu-

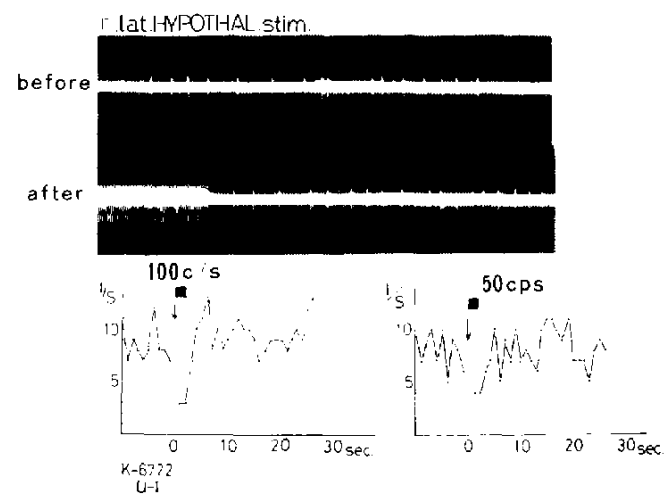

Fig. 3 The SON unit activities before and after stimulation of the ipsilateral lateral hypothalamus. Lower left: A firing frequency of unit discharges at stimulation of 0.3 volt, $100 \mathrm{~Hz}$. Lower right: 0.3 volt, $50 \mathrm{~Hz}$.

larly pronounced when the stimulation was ipsilateral to the SON from which unit recording was made. All these observations are interpreted as indicating that some interaction exists between the lateral hypothalamus in which there is the drinking center and the SON which is considered to be the locus of osmoreceptors.

\section{Unilateral lesion of the supraoptic nucleus- Traumatic diabetes insipidus}

\section{a. Complete unilateral lesion}

The SON of the anterior hypothalamus of cats was completely destroyed stereotactically on one side. An example of such cases is shown in Fig. 4, together with the time course of daily water intake and output as well as electrolytes and osmolarity of the serum and urine before and after the surgical operation.

Following destruction of the SON, water intake and output decreased until the 7th day, reached a level approximately treble as high as normal values on the 12 th to 14 th day, decreased again on the 14th to 15 th day and returned to the preoperative level in a matter of 20 to 30 days. In this particular case, little change occured in electrolytes and osmolarity of the serum and urine following destruction of the SON.

b. Incomplete unilateral lesion

Fig. 5 shows a case of unilateral destruction of the SON, in which case a coagulating electrode failed to reach the SON and hence produced an incomplete lesion. However, as can be seen from 


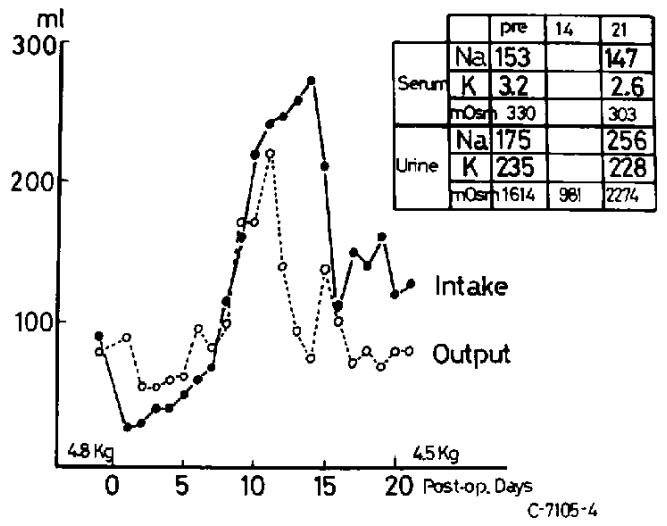

Fig. 4 Daily intake and output, as well as electrolytes and osmolarity of the serum and urine before and after complete unilateral lesion of the SON. Note increased intake and output at the 12 th to 14 th day.

histological pictures in Figs. 6 and 7, there was a decrease in population of cells in the SON (Fig. 7), as compared with the healthy side (Fig. 6), and also the evidence of chromatolysis, a finding indicating that the lesion was due to compression and edema. ${ }^{6}$ The water intake and output in this case, similarly as those in the foregoing case of the complete lesion of the SON, reached a peak between the 7th and 20th day after causing damage to the SON, still showed an upward tendency on the 30th day and was restored to almost normal by the 40th day. Here again, electrolytes in and the osmolarity of the serum and urine remained almost unchanged before and after the surgical procedure (Fig. 5). Thus, incomplete unilateral lesions of the SON resulted in polyuria and polydipsia but with no abnormalities in electrolytes in body fluids.

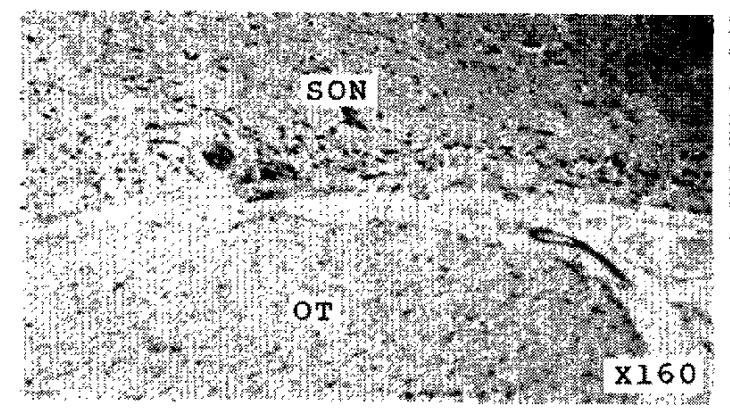

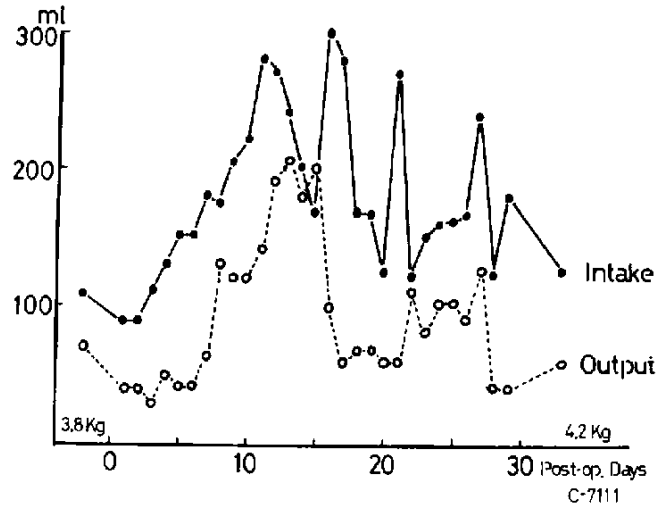

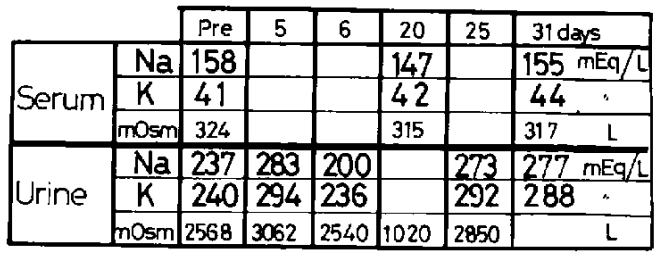

C-7111

Fig. 5 Upper: Daily intake and output before and after incomplete unilateral lesion of the SON. Lower : Electrolytes and osmolarity of serum and urine. See text for details.

Next, an investigation was also made of neurone activities of the SON contralateral to the SON lesion. The results are shown in Fig. 8. Neurone activities were noted to increase during and after injection of $2 \mathrm{ml}$ of $1 \mathrm{~mol} \mathrm{NaCl}$ into the carotid artery. In the diagram below, on the left is shown a coronal section of the brain as reproduced from F. 13.5 of the Jasper and Ajmon-Marsan's Atlas of cat where the SONs are indicated as black areas. Firing frequency of these unit discharges constructed at $1 \mathrm{sec}$. intervals are shown in Fig. 9. The upper diagram

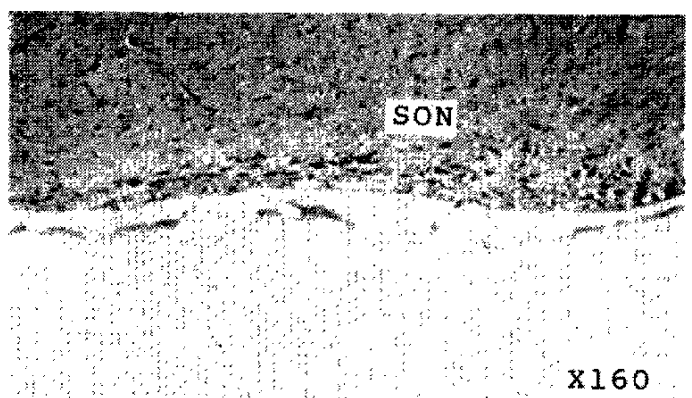

Fig. 6 and 7 Histological pictures in a case of Fig. 5. There is a decrease in population of cells in the SON with evidence of chromatolysis (Fig. 7), as compared with the healthy side (Fig. 6).

SON: the supraoptic nucleus, OT: the optic tract 


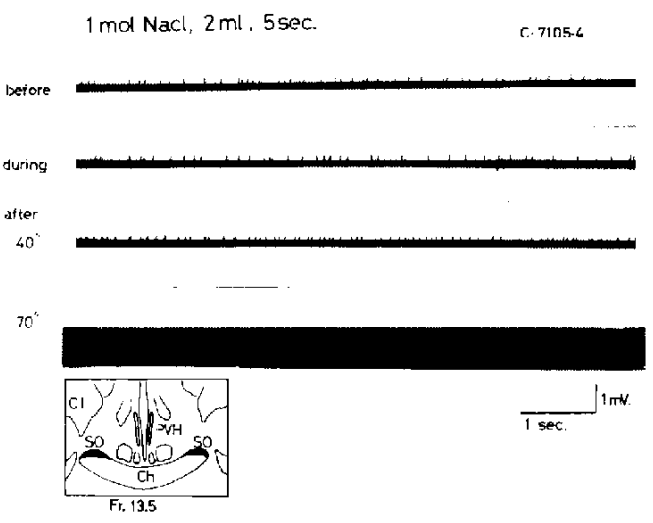

Fig. 8 Unit activities of the SON contralateral to the SON lesion before, during and after injection into the carotid artery of $2 \mathrm{ml}$ of $1 \mathrm{~mol} \mathrm{NaCl}$. In this diagram below at the left is shown a coronal section of the brain as reproduced from F. 13.5 of the jasper and Ajmon-Marsan's atlas of cat where the SONs are indicated as black areas.

shows changes in unit activities in response to injection of hypertonic saline, demonstrating a prolongation of response latency and a gradual increase in magnitude and prolongation of response in comparison with normal SON activities. The middle diagram represents responses to stimulation of the contralateral lateral hypothalamus, indicating that no marked augmentation of unit activities occured subsequently to their inhibition during stimulation. In the lower diagram illustrated are unit activity responses to the injection of hypertonic saline followed in 5 or 15 seconds by stimulation of the lateral hypothalamus. As can be seen, augmentation of response was not so distinct as in the normal group.

On the right column of Table 1, responses of 40 units in the contralateral SON to injection of hypertonic saline following lesion making in the unilateral SON. Of these units, $65.0 \%$ showed an increase in response, $10.0 \%$ showed a decrease and $25.0 \%$ did not show any response throughout. It becomes readily obvious that these relative proportions of response patterns are nearly identical to those for the normal group indicated on the opposite column of the table.

From these observations it is apparent that in cats with traumatic diabetes insipidus the spontaneous discharge rate of neurones of the $\mathrm{SON}$ is lower and their responses to osmotic changes

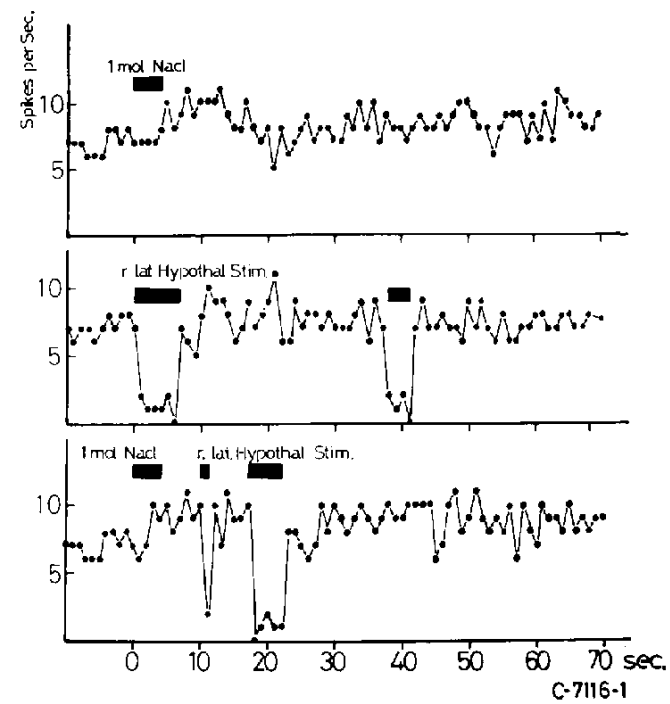

Fig. 9 A firing frequency of unit activities in Fig. 8. See text for details.

and neural stimulation are weaker than in normal cats. The osmolarity of and electrolytes in the serum and urine were also virtually within the normal range throughout the period of observation. These findings are quite similar to those obtained in human traumatic diabetes insipidus and, accordingly, one is justified in considering the SON-lesion cat prepared in this experiment as providing an experimental model of ample legitimacy for diabetes insipidus. ${ }^{1,13}$

\section{Unilateral lesion of the SON and lateral hypothalamus- Hypernatremia}

Fig. 10 shows a case in which the SON on one side and the lateral hypothalamus on the opposite side were damaged with exploring electrodes. In Fig. 11 illustrated is the location of the lesion in the ateral hypothalamus. In this case, polyuria and polydipsia persisted for 3 to 4 days following the artificial production of lesions; subsequently the water intake and output increased gradually for a period from the 4th to 13th day, then showed a steeply upward tendency forming a peak during a succeeding period from the 14 th to 24 th day, the increase lasting until around the 40th day. On the 7 th day after the surgical procedure, the serum $\mathrm{Na}$ was $180 \mathrm{mEq} / \mathrm{L}$ (Hypernatremia) and the plasma osmolarity was also elevated to $367 \mathrm{~m}$ $\mathrm{Osm} / \mathrm{kg} \cdot \mathrm{H}_{2} \mathrm{O}$. At that time the plasma $\mathrm{ADH}$ 


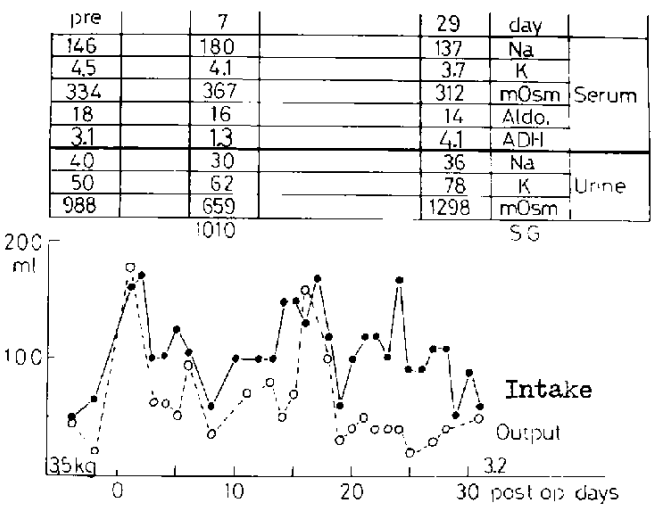

Fig. 10 Daily intake and output as well as electrolytes and osmolality of serum and urine. Plasma $\mathrm{ADH}$ and Aldosterone also are indicated. This case in which the SON on one side and the lateral hypothalamus on the opposite side were damaged. Polyuria and polydipsia persisted for 3 to 4 days following the artificial production of lesions, forming a peak during a succeeding period for the 14 th to 24 th day. At the 7 th day after the surgical procedure the serum Na was elevated. See text for details.

level was estimated by radioimmunoassay to be $1.3 \mathrm{pg} / \mathrm{ml}$, a value which corresponds to the lower limit of the normal range of ADH for this animal species. The plasma aldosterone remained substantially the same as before operation. On the $291 \mathrm{~h}$ postoperative day the water intake and output were found slightly increased but the serum electrolytes, the osmolarity of plasma and plasma ADH and aldosterone were all within the normal range.

The clinical pattern observed on around the 7 th postoperative day may be considered as implying that there was acute hypernatremia accompanied by a mild form of diabetes insipidus. A clinical condition which is reflected in such a pattern has thus been shown to be marked not only by hypernatremia (which has been considered to result simply from dehydration) but also, at least in some instances, by concurrent polyuria and may hence be described as acute hypernatremia with diabetes insipidus.

\section{Discussion}

Available evidence indicates that $A D H$ is synthesized mainly in the SON of the anterior hypothalamus and is transported being attached

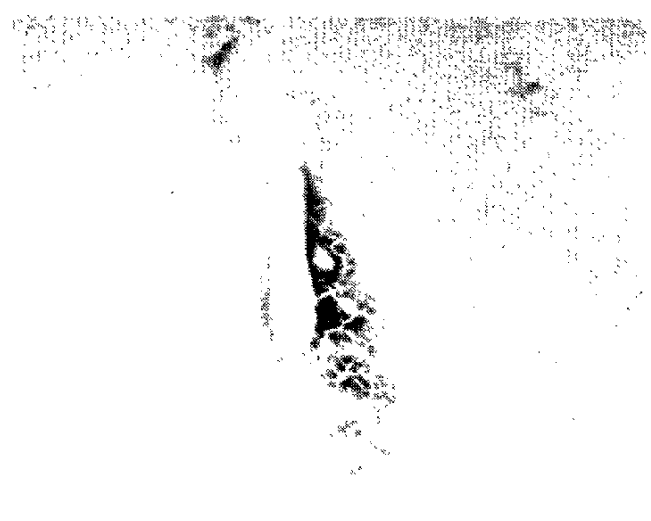

$x 200$

Fig. 11 This illustrates the location of the lesion in the lateral hypothalamus.

to a large carrier protein (Neurophysin), along the neurohypophysial pathway to be stored in the posterior lobe of the pituitary. ${ }^{34}$ The secretion of ADH is also recognized to be controlled and regulated by plasma osmolarity, ${ }^{5,15,34)}$ extracellular fluid volume ${ }^{30,31)}$ and higher centers. ${ }^{4.5 .16)}$ Osmoreceptors are sensitive enough to perceive as slight a rise in plasma osmolarity as $2 \%$ and, in response to this stimulation, initiate release of $\mathrm{ADH}$, from which the following sequence of phenomena ensues: promotion of renal reabsorption of water $\rightarrow$ increase in extracellular fluid volume $\rightarrow$ lowering of plasma osmolarity $\rightarrow$ inhibition of $\mathrm{ADH}$ secretion. In Addition, the volume receptors in the left atrium are stimulated by changes in circulatory blood volume and convey the stimulus to the hypothalamus. The baroreceptors in the carotid body and arcus aorta also have influence upon the secretion of ADH.

Since, however, what comes into question in the field of neurosurgery is the disorder of osmoreceptors per se, derangements of $\mathrm{ADH}$ secretion were investigated from a viewpoint of osmolarity in the present study. Investigations were 
also made on the role of osmoreceptors in $\mathrm{ADH}$ releasing disorder and in experimentally induced diabetes insipidus in the cat, and on the involvement of the lateral hypothalamus (regarded as the locus of the feeding and drinking centers) in these disorders as well as in hypernatremia resulting from disorders of osmoreceptors and the drinking center.

Osmoreceptors conceived by Verney ${ }^{34)}$ were probably the mixture of osmosensitive cells and neuroendocrine cells. ${ }^{35}$ ) Our study of 60 units of the SON of normal cats (Table 1) showed that $23.3 \%$ of the units studied were unresponsive to injection of hypertonic saline. This type of cells corresponds to what was termed neurosecretory cells by Vincent and Hayward ${ }^{35}$ and is more likely to form synaptic connections with such neural structures as the frontal lobe, limbic system, reticular formation and vagus than with osmosensitive cells. Diminished responses were exhibited by $8.3 \%$ of the cells, but it is not certain whether there are a group of cells, among osmosensitive cells, which are dissimilar to the rest of cells in physiological activity. Although omitted in this presentation, our experiment has demonstrated attenuated SON neurone activity in response to the administration of pitressin, suggesting the existence of a feedback mechanism that operates between plasma $\mathrm{ADH}$ and ADH secretion. Experimental evidence for interaction between the SONs was also obtained. ${ }^{32)}$ It is inferable therefore that the SON which is thought to be osmoreceptors has many other functions, e.g. functional relationships with other neural structures and the contralateral SON and feedback mechanism concerning $\mathrm{ADH}$, in addition to its responsiveness to osmotic changes.

By the way, diabetes insipidus may be classified into primary diabetes insipidus of unknown etiology and secondary diabetes insipidus due, for example, to trauma and brain tumor. ${ }^{26)}$ It is well known that diabetes insipidus due to head injury is usually transient in duration and subsides in days or weeks. According to Shucart and Jackson, ${ }^{291}$ diabetes insipidus following head injury or surgery in the hypothalamopituitary area can be divided into four types, i.e. transient, triphasic, permanent and intermediate. Diabetes insipidus is of rare occurrence in the cat as reported previously by Green and Farrow ${ }^{13}$ and the legitimacy of comparing our cat preparation to human diabetes insipidus is open to question. However, as can be seen from the case illustrated in Fig. 4, unilateral complete lesion of the SON caused polyuria of transient type but without any appreciable changes in electrolytes and plasma osmolarity and the clinical course was similar to that of a corresponding condition in humans. Clinical experience tells that such a type of diabetes insipidus is due more often to hypothalamic dysfunction than pituitary dysfunction. In the case of incomplete lesion, probably edema and/or compression, of the SON as illustrated in Fig. 5, polyuria of transient type resulted and, in contrast with the foregoing case of complete lesion, a triphasic or polyphasic pattern was displayed. Actual clinical cases seem to be more frequently of such an incomplete SON lesion type. It is possible therefore to induce permanent diabetes insipidus by the experimental production of bilateral SON lesions.

In experimentally induced diabetes insipidus of the cat, polyuria was accompanied by polydipsia, water balance was virtually maintained and, accordingly, no changes were noted in serum electrolytes and plasma osmolarity. However, a study of unit discharges of the intact SON in a case of experimentally induced diabetes showed that the function of the injured SON was still diminished until the 30th day after production of the lesion when water intake and output had already been restored to normal. Recording of electrical activities made about 2 months after surgical procedure in another case demonstrated increased unit discharges, i.e. augmented responses to injection of hypertonic saline of lower concentrations. These findings suggest the existence of a compensatory function, in addition to interaction, between the SONs.

Mahoney and Goodman reported chronic hypernatremia without polyuria or polydipsia, and proposed that hypernatremia appears to be due both to derangement of the thirst mechanism and to an elevation of the osmotic threshold for antidiuretic hormone secretion. They classified some of the derangement of thirst and $\mathrm{ADH}$ secretion that can cause abnormalities of water metabolism in man. ${ }^{20}$ ) The etiology of hypernatremia has been the subject of many reported studies. $^{7,17,19.28 .37)}$ There is also a report stating that hypernatremia is caused primarily by a 
disorder of the regulating center of $\mathrm{Na}$ excretion. ${ }^{23,25)}$ Avioli, ${ }^{31}$ on the other hand, proposed a concept of resetting of osmostat. Welt ${ }^{37)}$ proposed the following criteria for essential hypernatremia: 1) the absence of overt dehydration, 2) the presence of ADH secretion, and 3) responsiveness of the kidney to ADH. Many are of the opinion that a diminution of thirst should be added to the above items. In this connection it is interesting to note that Stricker ${ }^{31)}$ demonstrated experimentally the existence of the thirsty satiety center as distinct from the thirst center. As already stressed by Fischer et $\mathrm{al}^{11)}$ and Myers, ${ }^{24)}$ the drinking center in the lateral hypothalamus plays an important role in the maintenance of water balance and importance has also to be attached to its relationship with osmoreceptors. Dorn and Rothballer ${ }^{7)}$ succeeded in the artificial induction of essential hypernatremia by injecting $\mathrm{AgNo}_{3}$ into the subarachnoid space at the optic chiasm of the cat. According to these authors, a distinct correlationship was noted to exist between the severity of lesion of the hypothalamus, particularly of the SON and its adjacent areas, and hypernatremia. They reported further that the urine concentrating power, urine volume, water intake and weight gain all did not differ significantly before and after surgery. These observations indicate that the concurrence of diabetes insipidus with hypernatremia is possible but does not presuppose insufficiency of $\mathrm{ADH}$ secretion.

In the case shown in Fig. 10 where lesions were caused both in the SON and the lateral hypothalamus, i.e. the drinking center, the surgical procedure resulted in slight hyposecretion of ADH and mild diabetes insipidus with concurrent development of hypernatremia. It is no wonder that Dorn and Rothballer ${ }^{71}$ obtained similar experimental results as ours, if $\mathrm{AgNo}_{3}$ employed in their experiment had really exerted an influence upon the lateral hypothalamus.

Anderson et $\mathrm{al}^{21}$ and Olsson ${ }^{25}$ hold the view that osmoreceptors are located around the third ventricle and essentially serve as Na detector for the cerebrospinal fluid. It is likely then that there might be some additional etiologic factors for hypernatremia, besides a damage to the SON and thirst center (Mahoney et al), a disorder of the SON and its neighboring areas (Dorn and Rothballer) and an injury to the lateral hy- pothalamus (the present authors).

\section{Acknowledgements}

The authors wish to thank Dr. T. Yamaji, 3rd Dept. of Medicine, University of Tokyo, for radioimmunoassay measurement of $\mathrm{ADH}$. This work was in part performed in Dept. of Neurology (Prof. R. J. Joynt), University of Rochester and Dept. of Neurosurgery (Prof. A. B. Rothballer), New York Medical College.

\section{References}

1) Anderson, B. and McCann, S. M.: The effect of hypothalamic lesions on the water intake of the dog. Acta. Physiol. Scand. 35: 312-320, 1956

2) Anderson, B.: Thirst and brain control of water balance. Am. Scientist 59: 408-413, 1971

3) Avoli, L. V., Earley, L. E. and Kashima, H. K.: Chronic and sustained hypernatremia, absence of thirst, diabetes insipidus and adrenocorticotrophin insufficiency resulting from widespread destruction of hypothalamus. Ann. Int. Med. 56: 131-140, 1962

4) Broocks, C. M., Uchiyama, J. and Lange, G.: Reactions of neurons in or near the supraoptic nuclei. Amer. J. Physiol. 202: 487-490, 1962

5) Cross, B. A. and Green, J. D. : Activity of single neurons in the hypothalamus: effect of osmotic and other stimuli. J. Physiol. (Lond.) 148: 554-569, 1959

6) Daniel, P. M.: The blood supply of the hypothalamus and pituitary gland. Brit. Med. Bull. 22: 202-208, 1966

7) Dorn, J. and Rothballer, A. B. : Essential hypernatremia. Arch. Neurol. 28: 83-90, 1973

8) Dudley, H. F., Boling, E. A., LeQuesne, L. P. and Moore, F. D.: Studies on antidiuresis in surgery: effects of anesthesia, surgery and posterior pituitary antidiuretic hormone on water metabolism in man. Trans. Am. Surg. Assn. 72: 94-107, 1954

9) Dyball, R. E. J. and Koizumi, K.: Electrical activity in the supraoptic and paraventricular nuclei associated with neurohypophysical hormone release. J. Physiol. (Lond.) 201: 711722 . 1969

10) Dyball, R. E. J.: Single unit activity in the hypothalamo-neurohypophysial system of brattleboro rats. J. Endocr. 60: 135-143, 1974

11) Fisher, A. E. and Coury, J. N.: Cholinergic tracing of a central neural circuit underlying the thirst drive. Science 138: 691-693, 1962

12) Fitzsimons, J. T.: The hypothalamus and drinking. Bril. Med. Bull. 22 : 232-237, 1966 
13) Green, R. A. and Farrow, C. S.: Diabetes insipidus in a cat. J.A.V.M.A. 164:524-526, 1974

14) Jewell, P. A.: The occurrence of vesiculated neurones in the hypothalamus of the dog. $J$. Physiol. (Lond.) 121: 167-181, 1953

15) Joynt, R. J. : Functional significance of osmosensitive units in the anterior hypothalamus. Neurology 14: 584-590, 1964

16) Kandel, E. R.: Electrical properties of hypothalamic neuroendocrine cells. J. Gen. Phy'siol. 47:691-717, 1964

17) Kastin, A. J., Lipsett, M. B., Ommaya, A. K. and Moser, J. M.: Asymptomatic hypernatremia. Am. J. Med. 38: 306-315, 1965

18) Koizumi, K. and Yamashita, H.: Studies of antidromically identified neurosecretory cells of the hypothalamus by intracellular and extracellular recordings. J. Physiol. (Lond.) 221: $683-705,1972$

19) Landolt, A. M., Yasargil, M. G. and Krayenbuhl, H. : Disturbances of the serum electrolytes after surgery of intracranial arterial ancurysms. J. Neurosurg. 37: 210-218, 1972

20) Mahoney, J. H. and Goodman, A. D.: Hypernatremia due to hypodipsia and elevated threshold for vasopressin release. Effect of treatment with hydrochlorothiazide, chlorpropamide and tobutamide. New Eng. J. Med. 279: 11911196, 1968

21) McLean, J. P., Lipsett, M. B., Li, M. C., West, C. D. and Pearson, O. H. : Regulation of salt metabolism after hypohysectomy in man. J. Clin. Endocr. Metab. 17: 346-355, 1957

22) Mills, I. H., Bamforth, J., Hindle, W. and Goadby, H. K.: The control of sodium and aldosterone metabolism in patients with diabetes after hypophysectomy. J. Endocr. 28: 4-5, 1964

23) Mouw, D. R, and Vander, A. J.: Evidence for brain $\mathrm{Na}$ receptors controlling renal $\mathrm{Na}$ excretion and plasma renin activity. Am. J. Physiol. 219: 822-832, 1970

24) Myers, R. D.: Chemical mechanisms in the hypothalamus mediating eating and drinking in the monkey. Ann. N.Y. Acad. Sci. 157: 918-933, 1969

25) Olsson, K.: Further evidence for the importance of CSF Na${ }^{-}$concentration in central control of fluid balance. Acta. Physiol. Scand. 88: 183-191, 1973

26) Randall, R. V., Clark, E. C. and Bahn, R. C.: Classification of the causes of diabetes insipidus. Proc. Staff Meet. Mayo Clin. 34: 299-302, 1959

27) Ross, E. J., Van't Hoff, W., Crabbe, J. and Thorn, G. W.: Aldosterone excretion in hypopituitarism and after hypophysectomy in man. Am. J. Med. 28: 229-238, 1960

28) Shimizu, K.: The supraoptic and pituitary diabetes insipidus (Japanese). Nihon-Rinsho 33: 10-17, 1975

29) Shucart, W. A. and Jackson, I. : Management of diabetes insipidus in neurosurgical patients. $J$. Neurosurg. 44: 65-71, 1971

30) Smith, H. W. : Salt and water volume receptors, Am. J. Med. 23: 623-652, 1957

31) Stricker, E. M. and Jalowiec, J. E. : Restration of intravascular fluid volume following acute hypovolemia in rats. Am. J. Physiol 218: 191-196, 1970

32) Teramoto, S.: Experimental study of diabetes insipidus. Excerpta Medica 293: 191, 1973

33) Timmons, R. L. and Gordon, S. D.: Water and salt metabolism following pituitary stalk section. Neurology 13: 790-800, 1969

34) Verney, E. B.: The antidiuretic hormone and the factors which determine its release. Proc. Roy. Soc. B. 135: 25-106, 1947

35) Vincent, J. D. and Hayward, J. N. : Activity of single cells in osmoreceptor-supraoptic nuclear complex in the hypothalamus of the waking rhesus monkey. Brain Research 23: 105-108, 1970

36) Welt, L. G., Seldin, D. W., Nelson, W. P., German, W. J. and Peters, J. P.: Role of the central nervous system in metabolism of electrolytes and water. Arch. Intern. Med. 90: 355-378, 1952

37) Welt, L. G.: Hypo- and hypernatremia. Ann. Int. Med. 56: 161-164, 1962

38) Wise, B. L.: "Fluid and Electrolytes in Neurological Surgery.", Charles C Thomas, Springfield, 1965

39) Wise, B. L. : The management of postoperative diabetes insipidus. J. Neurosurg. 25: 416-420, 1966 